\title{
A rare case of sinoatrial nodal reentrant tachycardia (SANRT) with underlying intermittent wolf parkinson white (WPW) syndrome
}

Rohit Kalia ${ }^{1 *}$, Taranpreet Kaur ${ }^{1}$ and Bodh Das ${ }^{2}$

*Correspondence: doctor.kalia@yahoo.com

'Department of Internal Medicine, Lincoln Medical and Mental Health Center, Bronx, New York, USA.

${ }^{2}$ Department of Cardiology, Lincoln Medical and Mental Health Center, Bronx, New York, USA.

\begin{abstract}
We present a case presenting with narrow complex SANRT converting into wide complex WPW syndrome upon administration of Adenosine in an asymptomatic patient without any structural heart disease. A 64 year old patient was referred from outpatinet clinic to the ER for tachycardia and found to have SVT (SANRT type) with narrow QRS tachycardia with HR of 188 . He was given one dose of adenosine $6 \mathrm{mg}$ IVP for SVT and his heart rate decreased to 80s and subsequent EKGs were suggestive of WPW syndrome. Patient did not have history of WPW syndrome. He was subsequently admitted to telemetry floor for further monitoring. Patient reported excellent functional state and had no risk factors for coronary artery disease. Physical exam was unremarkable except tachycardia. He was maintained on carvedilol $6.25 \mathrm{mg}$ bid. Post-Adenosine EKGs revealed WPW syndrome and disappearance of Electrical alternans. Cardiology service was consulted and suggested that patient had Intermittent WPW since previous EKGs didn't show WPW syndrome and response to adenosine suggests sinusnodal reentrant tachycardia. ECHO revealed normal ventricular function without any structural abnormalities. Patient was subsequently discharged and followed up in the cardiology clinic without any further symptoms.
\end{abstract}

Keywords: WPW syndrome, SANRT, sinoatrial nodal reentrant tachycardia, WPW syndrome without structural heart disease

\section{Introduction}

SA nodal reentrant tachycardia or SANRT is an uncommon arrhythmia, that usually occurs in patients with structural heart disease [1]. In patients referred for electrophysiologic studies due to Electrocardiogram (EKG) showing a supraventricular tachycardia (SVT), SANRT comprises from 2 to 17 percent of these cases $[2,3]$. The actual incidence of this arrhythmia may be higher than appreciated since many patients are asymptomatic and are not referred for electrophysiologic study. SANRT is a type of supraventricular reentrant tachycardia which originates in the sinus node. It typically lasts from a few minutes to several hours. Although most patients are asymptomatic, it can also present similar to other types of SVT with palpitations, lightheadedness, and dizziness. Between episodes of SANRT the heart rate and rhythm remain entirely normal. It responds to measures that stimulate the vagus nerve as sinus node is richly supplied by it.

WPW syndrome is a pre-excitation syndrome of the heart where there is an abnormal accessory conduction pathway between atria and ventricles, called "bundle of Kent". This abnormal tract bypasses the AV node. This tract can stimulate the ventricles prematurely. WPW syndrome is rare, with its Incidence being $0.1 \%$ to $0.6 \%$ in general population [4]. Coexisting SVT and WPW syndrome with an accessory pathway could be very dangerous and lead to ventricular arrhythmias.

We describe a case presenting with narrow complex SANRT converting into wide complex WPW syndrome upon administration of Adenosine in an asymptomatic patient without any structural heart disease.

\section{Case report}

A 64 year old male patient with past medical history of Duodenal Ulcer (Gastrolntestinal bleed in 2008), Benign Prostate Hyperplasia, and Nephrolithiasis presented to his medicine clinic for regular follow up. He was asymptomatic in the outpatient clinic but was found to have tachycardia. He was subsequently referred to ER for further evaluation. EKG was suggestive of SVT (SANRT type) with narrow QRS tachycardia with HR of 188 (see EKG \#1). He was given one dose of adenosine 6 mg IVP for SVT and his heart rate decreased to 80 s and subsequent EKGs were suggestive of WPW syndrome (see EKG \#2 and EKG\#3). Patient did not have history of WPW syndrome. He was subsequently admitted to telemetry floor for further monitoring.

Patient reported excellent functional state and had no risk factors for coronary artery disease. Physical exam was unremarkable except tachycardia. Serial troponins were $<0.015-0.060-0.051-0.029$, which were thought to be mildly elevated due to increased demand (normal $<0.015$ ). Chest X-Ray was unremarkable. Patient was initially started on ACS protocol medications, which was subsequently stopped due to mild troponin leak, which trended down and was thought to be secondary to tachycardia (supply/demand). He was given carvedilol $6.25 \mathrm{mg}$ bid. Post-Adenosine EKGs revealed WPW syndrome and disappearance of Electrical alternans. Cardiology service was consulted and suggested that patient had Intermittent WPW since previous EKGs didn't show WPW syndrome and response to adenosine suggests sinus nodal reentrant tachycardia. Echocardiogram revealed normal 
Kalia et al. Internal Medicine Inside 2013,
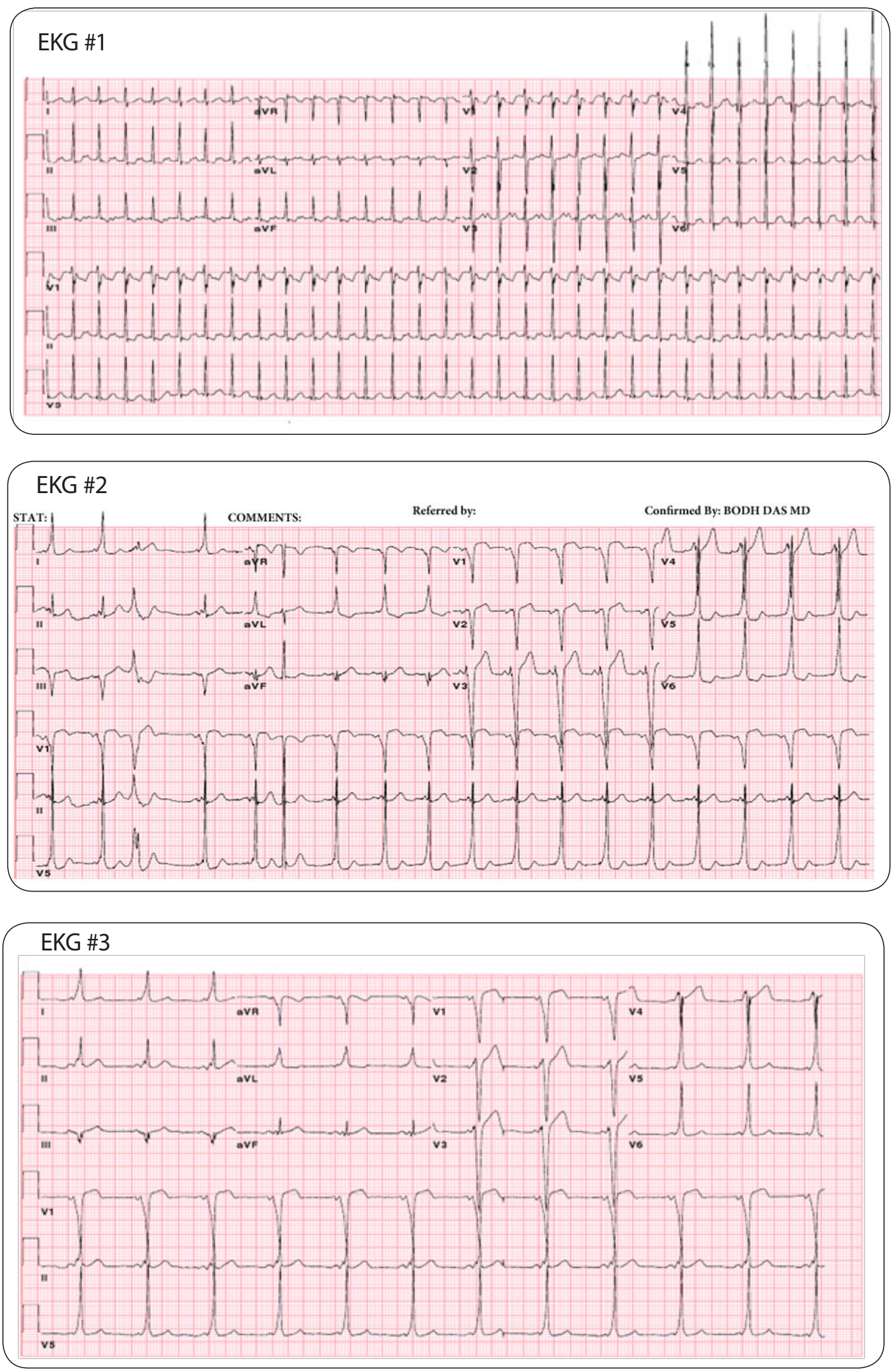
ventricular function without any structural abnormalities. Patient was subsequently discharged and followed up in the cardiology clinic.

\section{Discussion}

In 1943, Barker and co-workers described reentry tachycardias reporting "a circus rhythm could be accommodated in auricular muscle and in one of the specialized nodes at known rates of conduction and with cycle lengths such as occur in paroxysmal tachycardia" [5]. Heterogeneity of different types of Reentrant tachycardias was not appreciated at that time for few subsequent years due to lack of invasive electrophysiology until in 1968, when Han, Malozzi and Moe finally demonstrated the existence of sinoatrial echoes [6].

Most of the previous SANRTs described are in patient with structural heart pathology. Our case presented with narrow complex SANRT converting into intermittent wide complex WPW syndrome in an asymptomatic patient without any structural abnormalities on Echocardiography. In this case, the conduction in the accessory pathway was thought to be equivalent to $A V$ nodal conduction, therefore SANRT converted into intermittent WPW syndrome. In contrast, if accessory pathway conduction is more than AV nodal conduction, it could lead to Wide QRS tachycardia with increased risk of V-tach or V-fib.

SANRT reentrant circuit originates in the SA node itself, similar to that of normal sinus rhythm so that the $P$ waves on EKG appear to be normal compared to intraatrial reentry type of SVTs which have a P wave morphology that differs from that of normal sinus rhythm. The exact mechanism of SA nodal reentry is still not known but some hypothesis include:

a. Reentry within the SA node [9].

b. Reentry involving the SA node and perinodal tissue, based on a number of studies that have suggested the reentrant loop involves more than the SA node itself $[2,3,4,10,11]$.

c. Reentry using the SA node as the refractory center around which reentry occurs, although there is limited evidence for this potential mechanism [11].

Initial management in hemodynamically stable patients for an acute episode can be achieved with vagal maneuvers and adenosine. For Chronic suppressive pharmacotherapy, digitalis, beta blockers or calcium channel blockers are effective in controlling SVT when the reentrant tract involves the sinus node. Beta blockers have not been extensively studied for SANRT however, in one single center cohort study [12] beta blockers failed to prevent induction of SANRT, whereas digitalis analogue, amiodarone and Verapamil were successful in doing so. Ablation therapy is another option but it can damage the sinus node leading to requirement for a pacemaker placement.

However AV node blockers should be avoided in atrial fibrillation and atrial flutter with WPW or history of it; these include adenosine, diltiazem or other Calcium Channel blockers and beta blockers. They can exacerbate the syndrome by blocking the heart's normal electrical pathway and therefore favoring transmission through the pre-excitation pathway. This can lead to dangerous ventricular arrhythmias.

Procainamide, amiodarone, and cardioversion are treatment options for conversion of tachycardia found in patients with known underlying WPW syndrome. Flecainide has also been used for WPW syndrome as a Non FDA label, however like many other antiarrhythmics, it should be used with caution given its proarrhythmic effects as described in CAST trial and should be avoided in asymptomatic patients, in patients with recent myocardial infarction, for suppression of PVCs or in patients with chronic atrial fibrillation [13].

\section{Competing interests}

The author declare that they have no competing interests.

Authors' contributions

\begin{tabular}{|l|c|c|c|}
\hline Authors' contributions & RK & TPK & BD \\
\hline Research concept and design & $\checkmark$ & -- & -- \\
\hline Collection and/or assembly of data & $\checkmark$ & -- & -- \\
\hline Data analysis and interpretation & $\checkmark$ & -- & \\
\hline Writing the article & $\checkmark$ & -- & -- \\
\hline Critical revision of the article & -- & $\checkmark$ & $\checkmark$ \\
\hline Editing the article & -- & $\checkmark$ & $\checkmark$ \\
\hline Final approval of article & $\checkmark$ & -- & -- \\
\hline
\end{tabular}

\section{Publication history}

EIC: Fabio Angeli, University of Perugia, Italy. Received: 28-Aug-2013 Revised: 21-Oct-2013

Accepted: 26-Oct-2013 Published: 08-Nov-2013

\section{References}

1. Pahlajani DB, Miller RA and Serratto M. Sinus node re-entry and sinus node tachycardia. Am Heart J. 1975; 90:305-11. I Article I PubMed

2. Childers RW, Arnsdorf MF, De la Fuente DJ, Gambetta M and Svenson R. Sinus nodal echoes. Clinical case report and canine studies. Am J Cardiol. 1973; 31:220-31. I Article I PubMed

3. Paulay KL, Varghese PJ and Damato AN. Sinus node reentry. An in vivo demonstration in the dog. Circ Res. 1973; 32:455-63. I Article I PubMed

4. Rosner MH, Brady WJ, Jr., Kefer MP and Martin ML. Electrocardiography in the patient with the Wolff-Parkinson-White syndrome: diagnostic and initial therapeutic issues. Am J Emerg Med. 1999; 17:705-14. | Article | PubMed

5. Barker PS, Wilson FN and Johnston FD. The mechanism of auriculoproximal tachycardia. AmHeart J. 1943; 26:435.

6. Han H, Malozzi AM and Moe GK. Sinoatrial reciprocation in the isolated rabbit heart. Circ Res. 1968; 22:355. I Article

7. Gomes JA, Mehta D and Langan MN. Sinus node reentrant tachycardia. Pacing Clin Electrophysiol. 1995; 18:1045-57. I Article I PubMed

8. Josephson ME. Supraventricular Tachycardias. In: Clinical Cardiac Electrophysiology: Techniques and Interpretations 4th. Lippincott, Williams, and Wilkins, Philadelphia 2008.

9. Allessie MA and Bonke FI. Direct demonstration of sinus node reentry in the rabbit heart. Circ Res. 1979; 44:557-68. I Article I PubMed

10. Strauss HC and Bigger JT, Jr. Electrophysiological properties of the rabbit sinoatrial perinodal fibers. Circ Res. 1972; 31:490-506. I Article | PubMed

11. Kirchhoff CJ, Bonke FI, Allessie MA. Sinus node reentry: Fact or fiction?. In: Cardiac Arrhythmias: Where to Go from Here? Brugade $\mathrm{P}$, Wellens $\mathrm{HJ}$ 
Kalia et al. Internal Medicine Inside 2013,

http://www.hoajonline.com/journals/pdf/2052-6954-1-11.pdf

(Eds). Martinus Nijhoff, The Hague 1987. p.53.

12. Gomes JA, Hariman RJ, Kang PS and Chowdry IH. Sustained symptomatic sinus node reentrant tachycardia: incidence, clinical significance, electrophysiologic observations and the effects of antiarrhythmic agents. J Am Coll Cardiol. 1985; 5:45-57. | Article | PubMed

13. Preliminary report: effect of encainide and flecainide on mortality in a randomized trial of arrhythmia suppression after myocardial infarction. The Cardiac Arrhythmia Suppression Trial (CAST) Investigators. N Engl J Med. 1989; 321:406-12. | Article | PubMed

\section{Citation:}

Kalia R, Kaur T and Das B. A rare case of sinoatrial nodal reentrant tachycardia (SANRT) with underlying intermittent wolf parkinson white (WPW) syndrome.

Intern Med Inside. 2013; 1:11.

http://dx.doi.org/10.7243/2052-6954-1-11 